\title{
A Closer Look at an English Language Curriculum of a Community College in Saudi Arabia
}

\author{
Islam A. AL-Murabit ${ }^{1}$ \\ ${ }^{1}$ King Abdulaziz University, Jeddah, Saudi Arabia \\ Correspondence: Islam A. AL-Murabit, King Abdulaziz University, JCC, P.O. Box 80283, Jeddah 21589, \\ Kingdom of Saudi Arabia. Tel: 966-2-287-0026 Ext. 555. E-mail: ialmurabit@kau.edu.sa
}

Received: June 17, 2012 Accepted: July 10, 2012 Online Published: July 11, 2012

doi:10.5539/elt.v5n8p226 URL: http://dx.doi.org/10.5539/elt.v5n8p226

\begin{abstract}
This study analyzes a foundation year's language curriculum of a Saudi community college which uses English as a medium of instruction with the aim of improving its curriculum. First, both terms 'curriculum' and 'syllabus' are defined followed by a brief historical account of curriculum studies. Then, theories informing curriculum and syllabus design, implementation, and evaluation are discussed including curriculum formation, development of objectives, different approaches to curriculum and syllabus types, how, where and when they can be implemented. Moreover, a contextual background about the college and its English language program and curriculum is provided. After that, the curriculum is discussed through analyzing several of its aspects including planning, needs analysis, goals, objectives, syllabus, taught materials, skills, teaching and delivery, testing and evaluation. Main curriculum challenges facing the concerned educators and learners are also addressed. The study concludes by advocating the focus on the underlying problems and major deficiencies in the current and similar curriculums instead of only dealing with their symptoms.
\end{abstract}

Keywords: English language, curriculum, syllabus, curriculum design, curriculum evaluation, TESOL, Saudi Arabia, community college

\section{Introduction}

The recent rise of the role of English as an international leading language of education, communication and business resulted in an increase of the importance of developing an effective TESOL curriculum to fulfill the needs of learners for a practical command of English rather than mastering typical school language courses (Richards, 2001). Therefore, evaluating language curriculum is essential for it to achieve its objectives. This study embarks on a theoretical and practical analysis of an English language curriculum, of a Saudi community college, in order to identify its strengths and weaknesses and consequently improve its design and implementation taking into consideration the contextual background of where the study took place. It is also hoped that institutions with similar curriculums, circumstances and contexts will benefit from the outcome and recommendations of this study in their efforts of improving their English language curriculum.

\subsection{Definitions}

Curriculum comes from the Latin word currere which means "a course to be run or the running of the course", yet it is a recent concept used to describe courses of study at universities and schools (McKernan, 2008). When dictionaries are consulted, the word curriculum or curriculums and curricula (in the plural form) refers to: "the courses offered by an educational institution", "a set of courses constituting an area of specialization" (Merriam-Webster's Collegiate Dictionary, $11^{\text {th }}$ Ed.) or "all the subjects that are taught in a school, college or university; the contents of a particular course of study" (Oxford WordPower, $1^{\text {st }}$ Ed.). However, there are more specific definitions of the term 'curriculum' in educational studies. The following are samples of these definitions:

"All interrelated set of plans and experiences which a student completes under the guidance of the school" (Marsh and Stafford, 1984 in Grundy, 1987, p. 25)

"All the learning which is planned and guided by the school, whether it is carried on in groups or individually, inside or outside the school" (Kerr, 1968 in White, 1988, p. 4).

"The curriculum is a structured series of intended learning outcomes. Curriculum prescribes (or at least 
anticipates) the results of instruction." (Johnson, 1967 in McKernan, 2008, p. 11).

"The curriculum of a school, or course, or a classroom can be conceived of as a series of planned events that are intended to have educational consequences for one or more students." (Eisner, 2002 in McKernan, 2008, p. 11).

"The aims, content, methodology and evaluation procedures of a particular subject or subjects taught in a particular institution or school system" (Carter \& Nunan, 2001, p. 221).

Concepts such as planning, goals, methods, content, context, forms of delivery and evaluation, which formulate the elements of any curriculum, could be independently or collectively drawn from the above definitions.

White (1988) and Markee (1997) draw the attention to the degree of confusion between two interrelated terms 'syllabus' and 'curriculum' especially in the British and American usage. "In a distinction that is drawn in Britain, 'syllabus' refers to the content or subject matter of an individual subject, whereas 'curriculum' refers to the totality of content to be taught and aims to be realized within one school or educational system. In the USA, 'curriculum' tends to be synonymous with 'syllabus' in the British sense" (White, 1988, p. 4). This study will adopt the British concept of the word 'curriculum' as a framework for its further discussions.

\subsection{Historical Background}

In order to understand the ongoing debates regarding curriculum development and implementation, one should have a brief account of the educational methods of teaching and learning from a historical point of view. Richards (2001) summarizes the relative dominance of the teaching methods in education during the past two centuries as follows:

Grammar Translation Method (1800-1900)

Direct Method (1890-1930)

Structural Method (1930-1960)

Reading Method (1920-1950)

Audiolingual Method (1950-1970)

Situational Method (1950-1970)

Communicative Approach (1970-present)

These methods had a direct effect on how the studies of curriculum have surfaced in the twentieth century's philosophical and educational debates. It could be said that the publications of the two American educationists Taba "Curriculum Development: Theory and Practice" (1962) and Tyler "Basic Principles of Curriculum and Instruction" (1949) laid the foundation of curriculum studies as a branch of education in the last century (White, 1988). Richards (2001) declares that the later book by Ralph Tyler "brought about a revival in curriculum studies throughout the 1950s" through his approach in developing curriculum which could be reduced to the following simple model:

$$
\text { Aims and Objectives } \rightarrow \text { Content } \rightarrow \text { Organization } \rightarrow \text { Evaluation (p. 39) }
$$

Furthermore, Richards (2001) holds that the notion of syllabus design was the starting point for the history of curriculum development in language teaching. Likewise, White (1988) argues that the English language teaching (ELT) had been generally isolated from curriculum studies because of several reasons. These reasons included the development of ELT out of the applied linguistics field, the late emergent of ELT as a profession with its own identity and the previous tendency of ELT practices to take place in private language schools and colonial education system away from the mainstream education. Thus, it was not a surprise that only during the 1990s, James Brown (1995) was able to describe his book "The Elements of Language Curriculum: A systematic Approach to program Development" as "the first book that examines language teaching in detail from a systematic curriculum perspective" (p. ix).

\section{Theoretical Background}

At the first quarter of the $20^{\text {th }}$ century, Franklin Bobbitt introduced the concept of objectives into curriculum studies which was further popularized by Ralph Tyler in the middle of the century through the models of behavioral objectives (McKernan, 2008). Tyler's principles resulted in developing linear and 'product-oriented' curriculums informed by technical interests (Grundy, 1987). However, this view was later challenged by the 'process' or the 'experience' approach to developing curriculum (Breen, 2001; McKernan, 2008; Slattery, 2006).

Freire (1970) declares in his famous book 'Pedagogy of the oppressed' that education supports one of two 
contrasting approaches: the 'banking' concept or the 'problem-posing' concept. In the first approach, learners are viewed as 'depositories', 'adjustable' and 'manageable beings' and consequently manipulated. Conversely, the second approach respects the human dignity and helps to emancipate the individual. The advocacy of developing curriculum as 'praxis' as opposed to 'product' is fundamental to Freire's work and the emancipatory interest in education (Grundy, 1987). Grundy (1987) furthers the views of Freire by highlighting that curriculum as 'praxis' involves two positive constitutive elements: action and reflection while the concept of curriculum as 'product' leads it to be evaluated against predetermined criteria which represent a problematic design to start with. Therefore, Grundy (1987) argues that the educational system often constrains teachers from achieving one of the exact goals the system advocates, which is the advancement of independent learning and respect for individualism.

Similar to the work of Freire, Apple (1990) advances the arguments of the neo-Marxist movement by raising 'critical' questions regarding 'hegemony', assumed 'neutrality' in education and the ideological functions of academic institutions regardless of the conscious or unconscious participation of their educators in serving these ideologies through the 'hidden curriculum' and the 'reproduction' of certain economic and ideological forces in the society. Likewise, Habermas (1971) alleges that forms of relationships and unequal social structures are legitimized in advanced capitalist societies through the technologization of science (in Grundy, 1987).

Contrary to the ongoing battle between the two contrasting views of curriculum mentioned above, Young (1998) argues that both views of curriculum, which are 'curriculum as fact' vs. 'curriculum as practice', are equally mystifying. While the former view presents knowledge as external to knowers and therefore introduces an understandable and unchangeable curriculum, the latter approach over emphasizes the subjectivity and the social construction of reality which the curriculum is affected by.

In the same context, Grundy's book: Curriculum Product or Praxis (1987) warns against the 'severe problems associated with the objectifying approach to curriculum evaluation'. Equally, McKernan, who is an advocate of viewing curriculum as a 'process' or a 'continuous educational experience', rather than a 'product' or a 'behavior', argues throughout his book: Curriculum and Imagination (2008) against the philosophy of the outcomes-based education (OBE) movement, which pushes for the view of assessment in education through national standards (Breen, 2001).

Similar to the two contrasting view of curriculum as 'product' or as 'process' or 'praxis', when it comes to formulating curriculum objectives, two contrasting approaches emerge. The first approach advocates the use of objectives such as in the work of Brown (1995) who discussed and listed 15 reasons to argue why stating curriculum objectives is beneficial. In contrary, others argue against the use of objectives such as McKernan who allocated a whole chapter in his book: Curriculum and Imagination (2008) to discuss what is perceived as 26 limitations of the objective model in curriculum. These two contrasting views still nourish the theoretical debates around curriculum design up until today. In fact, McKernan (2008) claims that the literature and discussion about objectives superseded any amount of literature or discussions covering any other concept related to curriculum design. This is not surprising as these contrasting views are deeply rooted in the two well-known major paradigms in educational research which are the positivist, objective or scientific paradigm in one side and the interpretive, constructive or natural paradigm in the other side as discussed in education literature (Cohen et al., 2007; Crotty, 2003; Ernest; 1994; Gage, 1989; Grix, 2004; Lather, 2006; O'Donoghue, 2007). The following is a brief example of what results from such debates about formulating objectives for the curriculum.

Grundy (1987) explains the issue of predetermination of the objectives as follows: It is anticipated that the design of the learning experience will be determined by the pre-specified objectives, while the selection and organization of the learning experience will be determined by the skills of the curriculum developers. Therefore, the technically informed curriculum insures the success of the 'product' through careful development of clear and specific objectives which inspired the 'teacher-proof' document: "set out clearly what you want and elaborate step-by-step how you intend that the objective should be achieved, and success is guaranteed. It's as easy as making a cake!" (Grundy, 1987, p. 31). However, McKernan (2008) argues that "predetermination of objectives limits or prevents the realization of instructional opportunities - it is a constraining system not allowing "teachable moments" to be pursued" (p. 76). In response to such arguments, Brown (1995) states the following under the title 'Objectives do not bite':

"The difference between the two teachers is that the teacher next door who uses objectives is at least attempting to define what she hopes to teach the students to do. She may never get it completely right, but at least she is attempting to do so. Teachers who are critical of objectives, often for emotional reasons, are avoiding one tool among many that might help them become better teachers... Clearly, my view is that the advantages of objectives 
far outweigh their disadvantages; in fact, with a little creativity, the disadvantages can be entirely avoided." (p. 95-96).

Surprisingly, after attacking the use of objectives in 26 discussion points, McKernan (2008) states the following in his concluding comments regarding objectives:

"The objectives model is the dominant form of curriculum planning in use internationally... In all fairness it does seem that the objectives model is indeed appropriate in areas of the curriculum that focus on training and skills, while the process model is more appropriate in those curriculum areas that focus on knowledge and understanding. Perhaps some sort of a compromise is possible.” (p. 82).

However, later on McKernan states that "It seems acceptable to me that a curriculum can be adequately designed without using objectives.” (p. 92).

Closely associated to the issue of curriculum objectives are the views of What should form a curriculum and How the curriculum should be formed. Lier (1996) introduces three foundational principles of a curriculum: Awareness, Autonomy, and Authenticity, or the AAA Curriculum for short which are briefly illustrated in Table 1, suggesting that these principles form a unity of epistemological and axiological beliefs.

Table 1. Principles of Curriculum (Lier, 1996, p. 11)

\begin{tabular}{|c|c|c|}
\hline & Epistemology & Axiology \\
\hline Awareness & $\begin{array}{ll}\text { - } & \text { focusing attention } \\
\text { - } & \text { role of perception }\end{array}$ & $\begin{array}{ll}\text { - } & \text { know what you are doing } \\
\text { - } & \text { conscious engagement } \\
\text { - } & \text { reflection }\end{array}$ \\
\hline Autonomy & $\begin{array}{ll}\text { - } & \text { self-regulation } \\
\text { - } & \text { motivation } \\
& \text { depth of processing } \\
\end{array}$ & $\begin{array}{ll}- & \text { responsibility } \\
\text { - } & \text { accountability } \\
\text { - } & \text { free choice } \\
\text { - } & \text { democratic education } \\
\end{array}$ \\
\hline Authenticity & $\begin{array}{ll} & \text { language use in life } \\
\text { - } & \text { relevance } \\
\text { - } & \text { communication }\end{array}$ & $\begin{array}{ll}\text { - } & \text { commitment to learning } \\
\text { - } & \text { integrity } \\
\text { - } & \text { respect }\end{array}$ \\
\hline
\end{tabular}

Moreover, Reid (1999) lists variety of models which influence the formation of the curriculum as follows:

1- Models of the nature of knowledge [ontology];

2- Truth-seeking strategies [epistemology];

3- Nature of learners;

4- Desirable characteristics of learners;

5- Relationships between teachers and learners;

6- The role of the teacher and effective teaching;

7- Models of curriculum itself.

What derives from the above mentioned models are different types of curriculums such as the ones discussed by McKernan (2008, p. 35-36):

1. Formal curriculum: The planned academic courses of study offered by the institution.

2. Informal curriculum: The extracurricular activities organized around the formal curriculum.

3. Null curriculum: The curriculum that schools do not teach but that is perhaps equally important as the formal curriculum.

4. Actual curriculum: The curriculum that is actually implemented.

5. Hidden curriculum: The curriculum that is latent or covert but present in school culture.

Consequently, these contrasting curriculums lay the foundation for developing different types of syllabus such as the structural, situational, topical, functional, skills and task-based syllabus which will be discussed with more details soon. A syllabus could be defined as "a plan of what is to be achieved through teaching and learning. It is part of an overall language curriculum or course which is made up of four elements: aims, content, methodology 
and evaluation." (Breen in Carter \& Nunan, 2001, p. 151). Despite the variation in size and style of syllabuses which could range from one or two pages to over a hundred as reported by Taylor (1970), it seems that there is a consensus over the concept of syllabus as summarized by Brumfit (in White, 1988):

1- A syllabus is the specification of school or college work organized in subsections defining the work of a particular group or class;

2- Often linked to time and specify ultimate goals;

3- Specify some kind of sequence;

4- Document of administrative convenience and it is negotiable and adjustable;

5- Specify what is taught not what is learned;

6- And it is a public document which expresses accountability.

Brown (1995) names seven types of syllabuses and summarizes their ways of organizing courses and materials as shown in Table 2.

Table 2. Syllabuses (Adapted from Brown, 1995, p. 7)

\begin{tabular}{|c|c|}
\hline SYLLABUSES & WAYS OF ORGANIZING COURSES AND MATERIALS \\
\hline Structural & $\begin{array}{ll}- & \text { Grammatical and phonological structures } \\
\text { - } & \text { Sequenced from easy to difficult or frequent to less frequent }\end{array}$ \\
\hline Situational & $\begin{array}{ll}- & \text { Situations (such as at the bank, supermarket and restaurant) } \\
\text { - } & \text { Sequenced by the likelihood students will encounter them }\end{array}$ \\
\hline Topical & $\begin{array}{ll}\text { - } & \text { Topics or themes (such as health, food and clothing) } \\
\text { - } & \text { Sequenced by the likelihood students will encounter them }\end{array}$ \\
\hline Functional & $\begin{array}{ll}\text { - } & \text { Functional (such as identifying, reporting, correcting and describing) } \\
\text { - } & \text { Sequenced by some sense of chronology or usefulness of each function }\end{array}$ \\
\hline Notional & $\begin{array}{l}\text { - } \quad \text { Conceptual categories called notions (such as duration, quantity, location) } \\
\text { - Sequenced by some sense of chronology or usefulness of each notion }\end{array}$ \\
\hline Skills & $\begin{array}{l}\text { - Skills (such as listening for gist, listening for main ideas, listening for } \\
\text { inferences and scanning a reading passage for specific information) } \\
\text { - } \quad \text { Sequenced by some sense of chronology or usefulness of each skill }\end{array}$ \\
\hline Task & $\begin{array}{l}\text { - Task or activity-based categories (such as drawing maps, following directions } \\
\text { and following instructions) } \\
\text { - } \quad \text { Sequenced by some sense of chronology or usefulness of tasks }\end{array}$ \\
\hline
\end{tabular}

Brown acknowledges that often two or more of these types of syllabuses are mixed together. However, Breen (2001) reduces some of the different but yet similar types of syllabus to suggest the existence of four main types of syllabus in nowadays language curriculum: formal, functional, task-based and process.

As it should be obvious by now that the contrasting curriculums lay the foundation for developing different types of syllabus as discussed above, Similarly, the choice of teaching methods, materials and evaluation will be directly affected by the different philosophies, models and types of curriculums highlighted above only to insure that the different views feeding the ongoing debates about curriculum in the educational research and practices are far from coming to a consensus at any time in the near future.

Moreover, I would like to stress that knowledge without practical implications; could easily drift educational research into the realm of idealism, fantasies and empty verbalism. Therefore, one should demand practical alternatives as it is not realistic to expect all teachers in the curriculum to express and exercise 'ideal' and probably 'romantic' characters as described in the following teacher model of Mckernan's:

"The teacher is a model of one who is open-minded and critical of prejudiced views. In short, he or she teaches to enhance multicultural understanding and acceptance of and respect for various groups in society" ... "Even the shift from traditional, fact-based teaching to one permitting inquiry and discussion will prove too demanding for some teachers. Teachers need to abandon this role of imparter of information." (p. 93-94).

Although every educator may not disagree with promoting such values of justness, fairness, equal opportunity, the need for freedom, innovation and creativity, the delivery of such values may not be as easy as believing in them. Therefore, in this context, I would like to reuse a quotation from Mckernan's teacher and inspirer which Mckernan himself used it in his book: "It is idle to criticize the objectives model as a strategy for design and 
development of curriculum if no orderly alternative can be found". (Stenhouse, 1975 as in McKernan, 2008, p. 84). Likewise, I will argue that relying on the open-mindedness and good-will of 'all' teachers who are working in the field of education to express good intentions, act professionally and responsibly throughout the curriculum development and implementation stages is simply a naive way of thinking and demonstrates unrealistic expectations. The existence of busy, incompetent, irresponsible, closed-minded, ill-informed, inexperienced and unskilled teachers always remains as an indisputable fact in education.

An additional point in this regard is the need for a system which caters to institutions with big numbers of students and teachers. Obviously, and for practical reasons, some form of accountability has to be implemented in order for these institutions to function properly and accomplish the goals they were established for. I further argue that we, as educators, seem to accept the notion of the need for systematic functions and accountability measures when it comes to running our personal affairs such as driving, working in or dealing with companies or interacting with other individuals including our own family members. It seems irrational then to expect from our educational systems to be successful without the application of similar regularities and regulations at least to a reasonable extent. This logic is expressed by Young (1998) in the following statement: "The concept of 'curriculum as practice' gives teachers a spurious sense of their power, autonomy and independence from the wider context of which their work is a part. It thus provides them with no way of understanding their own failure to make changes, except in terms of their personal inadequacies." (p. 28).

What I am calling for here is a balance between the extreme stretching of the two views of how curriculum should be built and function. Educators should integrate the good that each of the two views can offer for improving curricula. Could curriculum be integrated and presented as both 'product' and 'process' at the same time? I have no doubt that it can be done if the researchers in education work together and put aside their philosophical arguments which they have inherited from artificial 'wars' between the competing theories and paradigms.

\section{Contextual Background}

The investigated language curriculum in this study is implemented in a famous community college in Saudi Arabia which enrolls several hundreds of male students every year. The curriculum forms more than three quarters of the total courses and classes provided to the foundation year students who newly join the college. It aims to elevate language knowledge and skills of the students to a level which allows them to pursue their studies in various subjects using English as a medium of instruction. However, in order to analyze this curriculum, discuss the challenges associated with it and suggest ways of addressing these challenges, brief background information about the context and the nature of this curriculum is given first.

\subsection{College Context}

Community colleges educational system was first introduced in the Kingdom of Saudi Arabia at the end of the 1990s. Today, there are more than 40 community colleges spread throughout the country. A main purpose of establishing this type of college is the quick fulfillment of job market needs. Another function of these colleges is to reduce the burden on universities which are under pressure of accepting the increasing number of high school graduates in a country whose population is growing rapidly.

Community colleges in Saudi Arabia, unlike the ones in the west, are supervised by universities. The Ministry of Higher Education aims to support these new colleges through their subordination to older and more experienced universities. Nevertheless, most community colleges are faced with great challenges such as the societies' views about the graduates of college-level institutions and the level of importance these institutions may enjoy as they are regarded inferior to universities (Shaw, 2006). In addition, the policies of admission in these colleges compel them in general to accept low level students who were not admitted into '4-year+' colleges in Saudi public universities. This means that most of these students join community colleges as the last available choice to be included in the free public higher education system in the country. Moreover, the students who join these colleges do not receive a monthly stipend from the government as other students in most public institutions in the system of higher education. Furthermore, most graduates of community colleges find it hard to pursue their education in Saudi public universities. This could be attributed to the stand of the Ministry of Higher Education regarding these colleges as it does not want them to be a backdoor for joining universities which defeats one of the main functions of establishing such colleges as mentioned above.

All of these challenges facing community colleges in Saudi Arabia work to hinder the efforts of improving the national image about these colleges and undermine the achievements of their students who as a result exhibit low morale, high dropout rates and express dissatisfaction when comparing their situation to those in other public educational institutions. 
Students in Saudi Arabia start studying English as a foreign language within the public school system in the $6^{\text {th }}$ grade. They receive a few classes of English instruction every week. Nevertheless, the English proficiency level of most high school graduates is poor and doesn't qualify them to pursue their studies in programs which employ English as a medium of instruction. Recently, there has been a trend among Saudi universities to introduce a 'foundation' or 'preparatory' year to improve the knowledge and skills of high school graduates before they join their desired majors at universities. Therefore, and as the demand for communication in English is growing worldwide especially in business, there is a tendency in most Saudi universities to include studying English as a main component of the foundation year for university students. Only, a limited number of public college-level institutions follow the universities' pattern and implement a preparatory or foundation year system which provides intensive courses of English. Among these institutions is the community college which its English curriculum is investigated in this study.

The college, which was established in 2003, doesn't differ much from the description of the Saudi community colleges' circumstances which are highlighted above. However, the college's choice to use English as a medium of instruction for its programs, its strategic location in a major Saudi city, and the support of the prestigious university which supervises it; in all gives it a higher profile than similar colleges in the Kingdom. Since male and female education in Saudi Arabia is generally segregated, all admitted students to this college are male Arabic speaking students who are either Saudi nationals or sons of Saudi mothers. The college has several programs leading to obtaining an associate diploma in computer network administration, graphic design, marketing, accounting, insurance, e-commerce, assistant pharmacologist and sales. Each of these programs consists of 64-70 credit hours except the sales program which is completed in only 36 credit hours. These programs are all taught using English except the sales program. Intensive English for beginners and low-intermediate level students is taught for two semesters which formulate the foundation year for all college students who want to join the above mentioned programs. However, the students in the sales program only study the first semester of the foundation year before they join their program which runs in Arabic. The English taught in the foundation year aims to prepare students to study their majors using English as the medium of instruction once they finish that year.

\subsection{English Program and Curriculum Context}

The college has four academic departments, three of them grant associate degrees in the above mentioned specializations and the other one functions as a supporting department through providing students with essential knowledge and skills in the areas of language, mathematics, communication skills and work ethics. This supporting department is called the 'General Required Courses' department or GRC. The GRC department is responsible for teaching a total of eight courses to the majority of the college's students. Among these eight courses are two English courses introduced in the foundation year: GRC111 and GRC112 which are also known as Levell and Level2 respectively. Each of these courses has a coordinator who reports to the GRC department head.

The number of the in-take students during the college's $3^{\text {rd }}$ and $4^{\text {th }}$ year of establishment ranged between 300 to 400 with the average of 30-35 students in relatively small size classrooms taught by only 10 English teachers; a condition which raised the teachers' concern about the quality of education at that time. As a result, more teachers were recruited in the past two years. Simultaneously, the number of students in the foundation year started to drop to about 200-300 students which resulted in an average of 15-20 students per classroom. Now, there are 14 English teachers in the GRC department who come from different parts of the world including USA, UK, South Africa, New Zealand, Egypt, Pakistan and India. They all hold post graduate certificates in teaching English as a second or foreign language.

Students undertake a placement test once they join the college to determine their English proficiency level and accordingly they get placed in GRC111 or GRC112. As a result of the placement test, usually about $90 \%$ of the students are placed in GRC111. Only a few students skip both courses to join their desired majors directly once they demonstrate a higher level of proficiency in the placement test and pass an interview with a written component. Each of the two English courses runs for a total of 13-14 weeks of instructions for the two main semesters (Fall and Spring) and consists of 20 contact hours per week, but results in only 3 credit hours of the total of 64-70 credit-hour associate degrees granted by the college.

The English language curriculum went through several stages since the start of the college. First, each of the two English courses (which at that time were called: English 107 and English 108) was only taught by one instructor teaching the same group of students for the entire 20 hours every week. The 20 hours were exclusively allocated to teach the language integrated skills textbooks: Headway then New Headway series. This strategy resulted in so 
many complaints from both teachers and students. Thus, the two courses' names were changed into GRC111 \& GRC112 with their 20 weekly hours broken down into:

- 10 hours for covering a 'Main Course Book' which became the level 1 and level 2 New Interchange and then Interchange ( $3^{\text {rd }}$ Edition) books respectively

- 5 hours allocated for 'Listening and Speaking' classes using level 1 and level 2 New Interchange Video Activity Books respectively

- 5 hours to focus on 'Grammar and Writing' skills in GRC111 and GRC112 using two textbooks: Keep Writing Book 1 and 2 respectively and English Grammar in Use simultaneously. The two textbooks adopted in GRC112 were recently changed to Facts and Figures to improve the reading skills of the students and First Steps in Academic Writing to assist them in advancing their writing skills. Consequently, these 5 hours became known as the 'Reading and Writing' classes in GRC112 vs. 'Grammar and Writing' classes in GRC111.

\section{Curriculum Analysis}

In this part of the study, the following elements of the current curriculum's design and implementation will be briefly discussed and analyzed: curriculum planning, conducting needs analysis, goals, objectives, syllabus, materials, skills, teaching and delivery and finally testing and evaluation.

\subsection{Planning}

Some sort of planning and organization of the various elements of the current curriculum such as the needs analysis, objectives, teaching, materials, testing and evaluation must have taken place when the curriculum was first introduced in the college several years ago. However, it could be concluded from reviewing documents and the further discussion in this study that the ones responsible for planning this curriculum may have implemented a packaged pedagogy through the choice of adopting ready-to-use textbooks and simply allowed them to make all the choices of approach, syllabus, techniques and exercises (Brown, 1995).

\subsection{Needs Analysis}

Needs analysis, which is also called needs assessment, "is defined by Richards, Platt, and Weber (1985, p. 189) as "the process of determining the needs for which a learner or group of learners requires a language and arranging the needs according to priorities." (Brown, 1995, p. 35-36). Conducting needs analysis has recently become one of the basic steps in the process of curriculum development and evaluation. This is because involving teachers and learners in the process of developing the curriculum and the needs of the learners can determine the success or failure of such curriculum (Carroll in Graves, 2007).

Similarly, teachers in this college often report lack of motivation among a big number of students. This problem is not specific to English courses and could be attributed partially to the current situations of the community colleges in the country as mentioned earlier in this study. Moreover, underachievement is very common particularly among young male students in this culture (Shaw, 2006). Nevertheless, part of the problem regarding the lack of motivation among students could be attributed to the passive role of students in choosing what and how they should study. Up until this date, there is no 'needs analysis' involving students has been conducted prior, during or after their courses of study and the development and evaluation of their current curriculum.

Not only were needs analysis not conducted in the current curriculum, but also it can be easily argued that the current curriculum doesn't cater to learners' needs by preparing them to study their academic majors using English as the medium of instruction. Therefore, some components of English for Academic Purposes (EAP) should have been introduced in this context; which is not the case here. On the contrary, their current curriculum caters to beginner and low-intermediate level students who could be more interested in studying English for general or social purposes. Likewise, the students are expected to use English in their future career. However, no English for Specific Purposes (ESP) courses are introduced either as components of the current curriculum or as separate courses once students depart from their foundation year to join their majors. It is important to reemphasize here that students only receive two courses of English language instruction throughout their program of studies in the college. These are the two foundation year courses: GRC111 and GRC112 or English level 1 and 2.

Probably it is useful here to bring into the discussion one of the theoretical foundation's points about what is anticipated from a curriculum to achieve. McKernan (2008) argues that for a curriculum to be truly educational, it has to lead the learners to unanticipated, rather than predicted, outcomes. However, I would argue that if such approach may be suitable to be partially applied in social sciences and art studies, it should not be adopted as the main or the only applied approach when teaching language to college students with the aim of preparing them to 
follow their programs of studies in English. Moreover, the above approach, which Mckernan and others advocate for, may not suit the current curriculum with respect to issues related to time constrains, low proficiency level of students and lack of pedagogical background knowledge of students. Therefore, I would suggest that a big number of high school graduates still need guidance throughout curriculum stages. For instance, it is not expected from most of the students at this level to differentiate between their need to study general or social English and their need to study English for Academic Purposes (EAP) or English for Specific Purposes (ESP) unless such issues are discussed with them.

\subsection{Goals}

Brown (1995) identifies curriculum goals as "general statements concerning desirable and attainable program purposes and aims based on perceived language and situational needs" (p. 71). The goals of GRC111 and GRC112 courses are summarized in short statements describing the general purpose of each. The statements of goals for the two English courses as stated in the official course description document are listed below:

GRC111: "This course is designed to provide students with language basics; to improve their ability to communicate in English; and to improve their understanding of written texts. In addition, the students should be able to use English in some different real life situations."

GRC112: "This course follows the multi-skills syllabus in which components of the course are linked. The course covers the four skills of listening, speaking, reading, and writing, as well as improving pronunciation and building vocabulary. Moreover, particular emphasis is placed on essential language functions, which develop the students' communicative skills and enable them to participate in simple communication on a wide variety of topics."

The level of the targeted audience from the two courses is obvious from the above statements with the use of the following phrases: "provide students with language basics" and "enable them to participate in simple communication". Therefore, there is an obvious contrast between the courses' realistic goals stated above which is to prepare beginner-level students to communicate in English and the perceived ultimate goal of the two courses which is elevating the language proficiency level of the students to an advanced degree which enables them to use English as the medium of instruction for their future college studies. Therefore, it is evident that there is a large gap of knowledge and skills between these two announced goals of the investigated curriculum.

Furthermore, on one hand, the two courses do not show the sequential link between them or how these two courses are related to each other. On the other hand, the courses also do not state their connection to any earlier or future stages in the learners' use of the language. This may be related to the adoption of 'ready-to-use' textbook packages and curriculums without adapting them to suit the current circumstances.

\subsection{Objectives}

Brown (1995) defines Instructional objectives of a course as "specific statements that describe the particular knowledge, behaviors, and/or skills that the learner will be expected to know or perform at the end of a course or program." (p. 73). A closer examination of the difference between the definitions of the goals and objectives reveals that the level of specificity is the most distinguishing characteristic between the two (Brown, 1995).

The objectives in the current curriculum are called "course competencies". This label or the "competency statements' may suggest a certain degree of association with the outcomes-based education view, as discussed earlier in this study, whereas the objectives of the syllabus may be expressed as target achievements (Breen, 2001).

With a quick glance at the official course description for both English courses, it becomes clear that the objectives of the courses, which are labeled as 'competencies', are adopted from the textbooks package. The same note mentioned above regarding the contrast between the actual and perceived goals of the curriculum also apply to the stated objectives of the two courses. The underlined words in the mentioned objectives below serve as samples to make this point clear:

GRC111 course competencies:

- Engage in short exchanges to provide and obtain simple personal information.

- Extract main ideas in short listening passages.

- Guess meaning of vocabulary limited to familiar social topics.

- Read short written material limited to selected topics. 
GRC112 course competencies:

- Determine to a limited degree attitudes and feeling of others.

- Produce short pieces of writing.

- Extract gist and main ideas from short conversations.

- Use imperatives and information questions with (how many /how much).

- Use basic politeness techniques.

- $\quad$ Use to a limited degree informal language and idioms.

Another point to be highlighted in this regard is that the statement which precedes the list of GRC111 course objectives reads as follows: "The students are required to ...". Using such a statement instead of the commonly used one 'Students will be able to or SWBATs' could suggest a philosophy of teaching which is more authoritarian in style. This assumption could be supported by the detailed emphasis in the syllabus on disciplinary issues regarding punctuality, attendance, ways of conduct and attitudes expressed during classes. All of these clues may suggest the expectation of a certain style of interaction between teachers and students in the classrooms which is argued by some researchers to be authoritarian; which in turn hardly promotes motivation in this culture (Shaw, 2006).

Although the syllabus of the current curriculum will be discussed in more details next, it is worthy to point out some differences between the objectives stated in the two main documents of the curriculum in discussion: the official course description and the course syllabus. While the objectives mentioned in the official course description document are longer, more coherent and comprehensive, the ones specified in the syllabus are quite the opposite. For instance, the objectives in the course description are 16 while they are only 6 in the syllabus. In addition, the syllabus' objectives, quite opposite from the objectives of the official course description, mix various skills, functions and situations in one statement rather than separating them. The following statements are examples of such claim:

GRC111 syllabus objectives:

- To read the provided short written texts to enhance their reading ability in reduced accent.

- $\quad$ To read and learn about life, work, countries, languages and nationalities.

- $\quad$ To describe \& write about jobs, places, houses, rooms, lanes and give directions of a route/street etc.

From the quotations above, it may be obvious that such objectives should be revised and rewritten to say the least. However, stating the objectives in such a way suggests a bigger pedagogical concern. A quick comparison between the above quoted objectives and the main components, taken from Mager (1975) and others, which are necessary to formulate good objectives as Brown (1995) suggests, should make the point clearer. These fundamental components of developing good objectives are:

- Performance: what is expected from the learner to be able to do at the end of the course?

- Conditions: describing the situation and conditions surrounding the performance

- Measure: the ways of observing and testing the performance

- Criterion: the considered sufficient level of performance accuracy

Another issue to be discussed here is the predetermination of the objectives. While the more recent syllabus of GRC112 (Fall 2009) stated several objectives for the course, the absence of such objectives in the old GRC112 syllabus (Fall 2006) may suggest a certain pedagogical stand with respect to the useful vs. harmful effects of the predetermination of learning objectives. This issue was discussed earlier during the debate between the views of the two groups illustrated in the arguments of Brown (1995) and McKernan (2008).

Furthermore, I would like to extract a sample from the current syllabus to illustrate the debate among researchers, as indicated by Breen (2001), about the best way for learners to reach the language production target. One of the stated objectives of GRC112 course syllabus reads as: "2. Recognize and contrast their own vocabulary limitations and how they can develop their vocabulary through word maps and collocation exercises so they can build usage in context." The point in debate is "whether to explicitly focus on formal features in teaching or more implicitly enable learners to notice the gap between their own production and the correct reformulations provided by a teacher or others as feedback" (Breen, 2001, in Carter \& Nunan, 2001, p. 154). The quoted objective above suggests a view which favors the later method over the former. However, Breen furthers demonstrates the existence of the problem by drawing the attention to "the discovery that, even after 
years of rich and meaningful input in content-based or immersion classrooms, learners continue to reveal non-target like features in their language production. Swain suggests this may be explained by the relative lack of opportunity for oral participation by learners in class (Swain, 1995)." (p. 154). Finally, Breen suggests that the solution to such problem might exist in developing 'follow-up tasks' in future task-based syllabuses: "This suggests that follow-up tasks which encourage a focus upon a learner's gaps in formal knowledge revealed during earlier more communicative tasks may be a feature of future task-based syllabuses". (p. 154).

Finally, it is probably noteworthy to highlight that the official course description of the two English courses discussed above have not been updated for quite some time in order to reflect some changes which took place later such as the change of textbooks and consequently the change of their stated goals and objectives. However, this does not come as a surprise since such documents are usually kept for formalities like keeping an official records and providing students with official course descriptions for the purpose of credit transfer.

4.5 Syllabus

A quick review of the official course descriptions and the course syllabuses illustrates an overlap and some redundancy between the two. However, in the view of the different types of syllabuses as illustrated in more details above by Brown (1995), the objectives specified in both mentioned documents could be mainly identified as a mix between functional and skill or task-based syllabus. The task-based learning or (TBL) involves the specification "of a sequence of communicative tasks to be carried out in the target language. Center to the notion of a communicative task is the exchange of meanings." (Willis \& Willis in Carter \& Nunan, 2001, p. 173). This does not come as a surprise when recalling that the textbooks used in the current syllabus, the Interchange series, are mainly compiled by Jack Richards whose name is closely associated with the communicative approach.

I would also like to record the following technical points regarding the syllabus of the current curriculum which may suggest some deeper implications.

First, no separate syllabus is prepared for any of the following classes which each occupy a total of $25 \%$ of the course contact hours throughout the semester:

- Grammar/Writing classes for GRC111

- $\quad$ Listening/Speaking classes for GRC 111

Second, the course schedules (outlines) specifying every week's title or theme for all course syllabuses in the current curriculum are all taken directly from the outline of the adopted textbooks.

Third, there is a great confusion and overlap between the information stated in the syllabus of GRC112 created for the classes of the 'Listening/Speaking' and 'reading/writing' regarding the learning resources (textbooks), teaching method, evaluation, objectives and course outline which could suggest a mistake in coping and pasting some content and information between different documents related to the course.

The above notes may emphasize the need for more careful planning, documentation and reassessment of strategies and procedures used during all stages of curriculum development.

\subsection{Materials}

Garforth (1966) reports John Dewey's argument that curriculum content should assist in 'freeing the life process for its own most adequate fulfillment'. As many components of curriculum do not concern the students in their real life situations, for the curriculum to be successful, it has to engage the learners in what matters to them and ignite their imagination (McKernan, 2008). In support of ways to apply these views, it is very easy to demonstrate that nowadays language teachers enjoy "a wider choice of alternatives in the focus, selection, subdivisions, and sequencing of the content of lessons than they had [30] years ago." (Breen, 2001, in Carter \& Nunan, 2001, p. 156).

Nevertheless, the materials used in the two English courses in the current curriculum heavily rely on textbooks as evident from the information mentioned above and the course syllabuses. All of the adopted textbooks mentioned earlier in this report are mainly prepared for beginners and low-intermediate level students. Although, the mentioned level matches the actual level of the students in the foundation year, this target low level which the students' level is expected to fit within, explains the source of the proficiency gap students experience once they pass their only two English courses introduced to them during the foundation year and start studying their majors using English as a medium of instruction.

Regarding the use of technology, it could be stated that technology is used mainly in the listening and speaking classes through a video activity CD that is combined with an activity textbook (New Interchange Video Activity $B o o k$ ). While the video clips in the CD maybe suitable for promoting listening skills, many exercises in the 
textbook are not directly related to listening, rather they require students to focus on reading written instructions and texts in order to reproduce grammar structures taught in the student's book. Moreover, the skill of speaking in the listening and speaking classes is mainly practiced through answering direct questions derived from the video activity book or the $\mathrm{CD}$ without an opportunity for promoting more meaningful interaction in the classroom. Furthermore, the class syllabus and textbook do not exhibit evidence of adequate opportunity to practice speaking through communication activities with the exception of delivering short presentations (2-3 minutes) in both level 1 and level 2 courses in addition to some limited role playing activities and classroom discussions in level 2. This may suggest that the choice of the mentioned textbook and CD package for listening and speaking restricts the opportunity for improving these two skills.

\subsection{Skills}

The way the disintegration of the main language skills is done in the present curriculum does not exhibit pedagogical coherence. The adopted main textbook (Interchange $3^{\text {rd }}$ Edition) applies an integrated-skills approach to language learning. However, the 'listening and speaking' skills are taught separately in both courses GRC111 and GRC112 as well as the 'grammar and writing' in GRC111 and the 'reading and writing' in GRC112. Perhaps, this way of distributing the course contents aims to place additional emphasis on the more interrelated skills which are 'listening/speaking' and 'reading/writing' separately and to devote more of the students' efforts and focus on improving these skills. However, I would argue that it would have been more productive to distribute the course hours and skills in either one of the two following ways:

- $\quad$ Reading/Writing + Listening/Speaking classes with elements of EAP or ESP in each

- Integrated Skills classes (Interchange) + EAP / ESP classes

\subsection{Teaching and Delivery}

After observation from internal and external evaluators, the form of delivery in the analyzed curriculum is mainly teacher-centered whereas the teacher represents the main source of knowledge and authority in the classroom with passive learning taking place among students and minimal occurrences of meaningful communication between teachers and learners.

Research in education and curriculum studies suggests that such a way of 'delivering' information could be counterproductive to the process of teaching and learning. McKernan (2008) asserts that the aim of education in Aristotle's view is to enable the learners to make their own decisions; likewise, the main purpose of education in John Dewey's view during the beginning of the $20^{\text {th }}$ century is the continuing growth of the person. Moreover, Burden and Williams (1998) argue that in order for the curriculum to promote thinking, all subject areas need to employ philosophy which also promote thinking because only introducing a few sessions of thinking skills will not do much to improve the curriculum. Therefore, McKernan (2008) stresses the importance for learner's autonomy and warns against passive learning where the teacher is the only authority in the teaching and learning process. Similarly, Brundage and McKeracher (1980) stress the following points in teaching adults such is the case in the present curriculum:

- Adults learn best when they are involved in developing their own learning objectives.

- Adult learners react to experience as they perceive it, not as the teacher presents it.

- Adults learn best when they have learned how to learn.

(Carroll in Graves, 2007, p. 6).

One reason for the above mentioned less productive ways of teaching and delivery may be partially attributed to the teachers' focus on covering the materials in the textbooks as Shaw (2006) describes teaching approach in the Gulf region: "teaching follows the textbook very closely; renewal of contracts of expatriate teachers depends on covering the textbook content, ensuring that the students perform well in the tests and preparing them for the annual examination" (p. 47).

\subsection{Testing and Evaluation}

There are 100 marks allocated for each English course. A minimum of $60 \%$ is required for students to pass any of the two courses. Course marks are distrusted as follows:

- $20 \%$ quizzes, homework assignments and class participation (main teacher).

- $15 \%$ listening/speaking activities and quizzes (L\&S teacher)

- $15 \%$ grammar/writing or reading/writing activities and quizzes (G\&W or R\&W teacher) 
- $20 \%$ mid-term exam

- $30 \%$ final exam

A quick review of several samples of the above mentioned tests will reveal a heavy reliance on structure and grammar in testing the students' command of the language. Moreover, not only the quizzes and homework assignments but also the mid-term and final exams are primarily based on the materials and exercises covered in the main textbook. This means that about two thirds of the evaluation marks of the whole course are only a reflection of students' mastery of knowledge and skills covered in such materials and exercises limited to the main textbook. Furthermore, the last third of the total evaluation mark which is divided between listening/speaking and grammar/writing or reading/writing also sticks to the materials covered in the textbooks allocated for these skills. I would assert that this way of testing, in addition to limiting students' abilities to explore and use the language, sends wrong signals to them that their success in the course is dependent on mastering the textbooks materials rather than the language knowledge and skills.

Another main problem regarding evaluation should be addressed. However, this problem is holistic in its nature and it is related to the language program as a whole. No other independent or standardized form of evaluation, besides the internal tests which are heavily reliant on textbooks, is used to determine the actual proficiency level of students once they pass each course or before they are admitted to their majors in the college. This means that students who pass GRC112 can immediately join their majors assuming that their language proficiency level enables them to pursue their studies using English as a medium of instruction. This mechanism explains the reason why teachers of other subjects constantly complain about the low proficiency level of English which students exhibit even after they pass the two English courses of the foundation year. Therefore, this way of testing and evaluation in the present curriculum could confirm Shaw's claim (2006) that evaluation in the current culture generally depends on the students' performance on routine tests and the emphasis of the assessment is not upon development or reform but rather upon control.

In my opinion, such in-house evaluations discussed above could be accepted only when English is taught as one of the traditional foreign language courses, but not when it is taught to qualify students for studying the rest of their courses and specialized subjects through English. It is widely practiced in western and other academic institutions to rely on standardized tests to determine the accurate level of the students before they are accepted in their desired programs. I think it is quite reasonable to suggest the application of similar process in this context.

\section{Challenges and Suggestions}

During the curriculum analysis section of this report, several challenges have surfaced through the discussion. Already the majority of these challenges have been addressed briefly above. However, in this section of the study, I will revisit some of these micro-level challenges and suggest ways of addressing them in further details. Moreover, I will discuss other macro-level challenges and the ways they should be addressed using a holistic approach of looking at the problem and looking for solutions.

\subsection{Bridging the Gap between the Target and the Reality}

With the continuous complaining concerning the low English proficiency level of students finishing the foundation year and in their attempt to improve the curriculum, the teachers of English held long meetings to discuss ways to improve the situation, formed a number of committees including a "Curriculum Committee" to suggest changes and solutions to the problem and as a result came up with several plans and recommendations for improving the current curriculum. These recommendations included applying stricter policies of admission for accepting high school graduates, conducting needs analysis, placing students into more accurate and hierarchical proficiency level courses, introducing standardized tests, introducing more English courses to be taught during the second and third year of students' programs of studies including EAP and ESP courses, adapting the materials in the textbooks to encourage more interaction in the classroom, implementing more interactive techniques of teaching, conducting peer observations, promoting professional development among language teachers, providing teacher training and much more.

Definitely, I would advocate for introducing more courses of English for the students to arrive at the desired announced level of proficiency. In addition, EAP and ESP classes and courses should be introduced to the curriculum. Furthermore, support programs ought to be implemented such as establishing a language club for students to freely practice English, guiding students through utilization of the newly installed language labs in the college, introducing classes of Computer-Assisted Language Learning (CALL) to enhance the practice of language skills, establishing study groups, encouraging student-tutor method. Moreover, students must be 
encouraged to be active participants in the learning-teaching process through teaching study skills and promoting additional language practice and interaction in the classrooms where learners are more challenged or stretched to employ their optimum abilities and skills. Consequently, classrooms should be made student-centered instead of teacher-centered.

However, despite the teachers' tremendous efforts to introduce such changes, only few minor changes took place in some of the above mentioned areas over the past few years. This could be attributed to the bureaucracy and the inflexibility in policies and laws governing the college as one of the public institutions of higher education in the country. For instance, any fundamental change in the curriculum such as adding new courses has to be studied and approved by a number of bodies including, the concerned academic department, the college council, the curriculum committee at the university and the university supreme council. In addition to the usual delays in such cases because of formalities, it is important to notice that each of these councils and committees may return the process to its starting point more than once for the purpose of making any major or even minor adjustments. Ironically, such changes may never take place before key persons who started the process move to another location or position. Moreover, other factors which may have contributed to the unchanged status quo include financial and logistics constraints and the control of the order of priorities through decision making policy makers.

In all fairness, it is important to highlight that while the college faces so many restrictions to make any fundamental changes to its English language curriculum such as adding other courses, it can practically exercise a reasonable amount of freedom with respect to the way the curriculum is delivered such as the teaching approach, the content of the teaching materials, the choice of the textbooks and the distribution of the contact hours. Although, such choices will not fix all the problems related to the curriculum, they could significantly improve the language curriculum at the college.

Recently, two external bodies (The British Council and a delegation from different community colleges in the UK) were consulted for the purpose of improving the English language program at the college. Both conducted observations and situation analysis during their visitations to the college. Similarly, both submitted written reports including several recommendations for changing the current curriculum. Most of these recommendations were previously made and documented by the college teachers in several events. However, not many of these recommendations were implemented. Nevertheless, if the concerns expressed by these external viewers are to be taken more seriously and their recommendations are to be implemented more quickly this time, the situation may change for the better. However, for these changes to become a reality any time soon is an assumption yet to be seen. Otherwise, more disappointment will result from such efforts as Slattery (2006) reminds us that "committees are sometimes formed to revise the philosophy of the university or school district, only to discover that their real concerns and problems are never clearly articulated and seldom addressed in practice" (p. 188).

To conclude the issue of bridging the gap between the target and reality in the present curriculum, I would like to report some of the recommendations of the head of the intensive English program (IEP) in the American University of Sharjah (AUS) in the United Arab Emirates. The IEP had a very similar story to the story of the establishment and the function of the English program discussed in this study. The IEP in AUS was established to prepare students for studying their future majors through English. After years of running the program, the head of the IEP arrived at similar recommendations and conclusions which the teachers in this curriculum arrived at. First, it is important to introduce standardized tests such as the TOFEL to determine the students' level of proficiency. Second, teaching English for Specific Purposes to the foundation year students should be introduced. Third, a minimum TOFEL score for entry into the program should be established; which will allow teachers to focus more on those students who can practically benefit the most from the program. (John Shannon in Graves, 2007).

\subsection{Adopted vs. Adapted Curriculum}

It has been reported in education research that the higher level of clarity and preciseness in drafting program goals which reflect the perceived needs of learners shall result in developing more effective curriculum including the development of clear objectives of what should be taking place in the language classroom (Brown, 1995). Indeed, it could be more convenient and less risky for teachers to abdicate the responsibility of developing an accurate and coherent curriculum by simply adopting a packaged pedagogy or allowing textbooks to make all choices for them (Brown, 1995). Nevertheless, such approach risks the whole process of the curriculum fulfilling its goals to start with. Probably it is useful here to quote Kevin Harris's argument (1982):

"Teachers are now finding themselves facing both de-skilling and devaluation of their labour power. This is most obvious in the areas of curriculum packages and technical innovations ... in many cases the existence of such 
packages has already deskilled some teachers' work to the level of distributing pre-chosen material, checking pre-set tests and general filling duties..." (in Grundy, 1987, p. 32).

In fact, when the curriculum is adopted from 'ready-to-use' curriculum packages, teachers are pressured to teach in the ways envisaged by the designers (Grundy, 1987). Therefore, for the current curriculum to reach the desired outcome, its goals, objectives, choice of materials and learning methods should be developed by the teachers themselves and reflect the students' real needs. Basically, the adoption and the over-reliance on textbooks have proven counter-productive in the current curriculum and therefore have to be changed.

It is hard for someone to argue that college and university level teachers especially in the language education field do not have a reasonable amount of freedom to modify the 'official syllabus' in more productive ways which fulfill the needs and serve the interests of their learners. In fact, teachers should explicitly involve their students in the decision making process through negotiation for the purpose of developing the actual syllabus of the classroom regardless of the external or official syllabus (Breen, 2001), which may serve as an official record kept for formalities.

\subsection{Teacher Education}

It is vital for teachers in any educational sittings to grow in their cognitive knowledge, skills and profession through continuous teacher development as well documented in teacher education literature and recommended by the experts and practitioners in the field of education (Evans, 2002; Evans, 2008). For the purpose of this study, the suggestion here is to provide training opportunities and encourage teachers to attend workshops and conferences related to curriculum development in general and language curriculum in particular. This shall refresh their knowledge in this regard and encourage them to take action in changing the status quo.

\subsection{Logistics Issues}

The circumstances and issues discussed above concerning the language curriculum in the college illustrate the need for a leadership solution. Up until now, there is no position of real leadership to supervise the whole English program and curriculum at the college. There is only one position of 'course coordinator' for each of the two English courses taught at the college. However, these two coordinators are kept busy with administrative duties for the courses they coordinate such as arranging for tests' settings, recording of marks and arranging course portfolios. In addition, they teach the same amount of hours as other teachers and do not have actual authority to implement any fundamental changes to the curriculum.

Moreover, Teachers in this curriculum teach 20 hours per week. As a result, most of them do not show much enthusiasm for being involved in repeated discussions and efforts for changing the current curriculum. In fact, teachers who are loaded with administrative work in addition to their heavy load of teaching may not have time not only to address curriculum challenges but also to properly prepare for their classes, plan more meaningful, creative and enjoyable exercises for their students like the ones they see in training courses for new methods and techniques for teaching.

Furthermore, when teachers are faced with heavy working loads, resistance from administrators, bureaucracy in the process of change, little support for their views as the experts in a particular field of education, pressure from higher authorities, and violations of their rights as employees, the majority of them become drained, burned-out, frustrated and cynical after so many attempts to improve their status quo.

Another technical issue which has practical implications regarding this curriculum is that there have been more changes introduced to one of the two English courses (GRC112) than the other (GRC111). This fact suggests the importance of coordinating efforts among teachers to reach the expected level of coherence between the two and only English courses at the college.

Finally, after discussing all of the above mentioned problems and challenges of the current curriculum throughout this report, the complexity of nowadays classrooms with more students coming to educational institutes less prepared to learn and less willing to work productively should be taken into account (Larrivee, 2000). Therefore, "those who work in education need to learn far more about the non-school world that young people experience, how it differs from the world that they experience through the curriculum and how we can help them strengthen the connections." (Young, 1998, p. 33). Nevertheless, it is as important to emphasize that some of these challenges such as the low achievement, lack of motivation and dropout rates among students in this college are not special to the English language program, but they also emerge in situations where students are studying other subjects using their first language. Therefore, this may suggest the existence of problems far rooted in the culture of the society as other researchers suggest (Gaad, Arif \& Scott, 2006; Shaw, 2006). 


\section{Conclusion}

The rapid and continuous change in technology, culture, required life skills and knowledge necessitate curriculum development (McKernan, 2008). On one hand, the new curriculum derived from such processes should cater to the learners' needs and fulfill their expectations as well as the expectations of the educators and other stakeholders who are concerned with the outcome of education. On the other hand, education experts suggest that it is much easier to introduce new curriculum or suggest ways of changing it than to implement such suggestions or to integrate different elements of curriculum into one coherent pedagogical package (Gaad, Arif \& Scott, 2006).

In admission of the adversity of designing and implementing an effective curriculum which promotes innovation, Markee (1997) reports the statement of Niccolo Machiavelli: "There is nothing more difficult to plan, more doubtful of success, nor more dangerous to manage than the creation of a new order of things" (p. 3). However, without such courage most problems, deficiencies, ineffective measurements and counterproductive practices related to curriculum will continue to obstruct the curriculum from achieving its intended goals.

I would like to end this study by emphasizing that half measures produce half results. Basically, an institution should not expect fundamental changes in the output if it does not apply fundamental changes to the input. Constant changing of teachers, textbooks, distributions of course timing, testing and grading policies, technology adaptations and issues alike are important to curriculum success. However, issues such as curriculum design, goals and objectives of curriculum, formation of syllabus, appropriateness of materials, focus of skills, methodologies of teaching, effectiveness of testing, and professional evaluation of curriculum are much more important issues to be addressed in order for education to achieve its ultimate objectives. Therefore, the policy makers in the concerned college and any other institution who are experiencing similar circumstances, which I think are many, have to take one of two decisions and consequently will arrive at two different outcomes. The first is to superficially address minor and technical deficiencies in a curriculum and the second is to fundamentally reevaluate the whole curriculum and act accordingly. It is like making a choice between addressing symptoms versus addressing a cause or an underlying problem of a patient. The first may take fewer efforts and provide temporarily comfort while the other may take more efforts but at the end may help treating the actual cause of the problem.

\section{References}

Apple, M. (1990). Ideology and curriculum (2nd edition). London: Routledge.

Breen, M. (2001). Syllabus Design. In Carter, R., \& Nunan, D. (2001). (Eds.). The Cambridge guide to teaching English to speakers of other languages. Cambridge: Cambridge University Press.

Brown, J. D. (1995). The Elements of language curriculum. New York: Heinle and Heinle. [TESOL]

Burden, R., \& Williams, M. (1998). Thinking through the curriculum. London: Routledge.

Carter, R., \& Nunan, D. (2001). (Eds.). The Cambridge guide to teaching English to speakers of other languages. Cambridge: Cambridge University Press.

Cohen, L., Manion L., \& Morrison, K. (2007). Research methods in education ( $6^{\text {th }}$ ed.). New York: Routledge.

Crotty, M. (2003). The Foundation of social research: Meaning and perspective in the research process. London: Sage.

Ernest, P. (1994). An Introduction to research methodology and paradigms. In Randor. H. (Ed.), Educational Research Monograph Series. Exeter: University of Exeter, Research Support Unite, School of Education.

Evans, L. (2002). What is Teacher Development? Oxford Review of Education, 28(1), 123-137. http://dx.doi.org/10.1080/03054980120113670

Evans, L. (2008). Professionalism, Professionality and the Development of Education Professionals. British Journal of Educational Studies, 56(1), 20-38. http://dx.doi.org/10.1111/j.1467-8527.2007.00392.x

Freire, P. (1970). Pedagogy of the oppressed, Ch. 2. In Golby, M., Greenwald, J., \& West. R. (Eds.), Curriculum design. London: Croom Helm.

Gaad, E., Arif, M., \& Scott, F. (2006). System analysis of the UAE education system. International Journal of Education, 20(4), 291-303.

Gage, N. (1989). The Paradigm wars and their aftermath: A "Historical" Sketch of Research on Teaching Since 1989. Educational Research, 18(7), 4-10. http://dx.doi.org/10.2307/1177163 
Garforth, F. (1966). John Dewey: Selected educational writings. In Golby, M., Greenwald, J., \& West. R. (Eds.), Curriculum design. London: Croom Helm.

Graves, K. (2007). (Ed.). Developing a new curriculum for adult learners. Alexandria, Virginia: Teachers of English to Speakers of Other Languages, Inc. (TESOL).

Grix, J. (2004). The Foundations of research. London: Palgrave Macmillan.

Grundy, S. (1987). Curriculum: Product or praxis. London: Falmer.

Larrivee, B. (2000). Transforming Teaching Practice: becoming the critically reflective teacher. Reflective Practice, 1(3), 293-307. http://dx.doi.org/10.1080/713693162

Lather, P. (2006). Paradigm proliferation as a good thing to think with: Teaching research in education as a wild profusion. International Journal of Qualitative Studies in Education, 19(1), 35-57. http://dx.doi.org/10.1080/09518390500450144

Lier, L. (1996). Interaction in the language curriculum: Awareness, autonomy \& authenticity. London: Addison Wesley Longman Limited.

Markee, N. (1997). Managing curricular innovation. Cambridge: Cambridge University Press.

McKernan, J. (2008). Curriculum and imagination: Process, theory, pedagogy and action research. London: Routledge.

Merriam-Webster's Collegiate Dictionary. (2004). $11^{\text {th }}$ Ed. Springfield, Massachusetts, USA: Merriam-Webster, Incorporated: An Encyclopedia BRITANNICA company.

O'Donoghue, T. (2007). Planning your qualitative research project: An Introduction to interpretivist research in education. Oxon: Routledge.

Oxford Wordpower. (1999). $1^{\text {st }}$ Ed. Oxford: Oxford University Press.

Reid, W. (1999). Curriculum as institution and practice: Essays in the deliberative tradition. London: Lawrence Erlbaum Associates, Publishers.

Richards, J. (2001). Curriculum development in language teaching. Cambridge: Cambridge University Press. http://dx.doi.org/10.1017/CBO9780511667220

Richards, J., Hull, J., \& Proctor, S. (2005). Interchange ( $3^{\text {rd }}$ Edition) series. Cambridge: Cambridge University Press.

Shaw, K. (2006). Muslim education in the gulf states and Saudi Arabia: Selected Issues. In Griffin, R. (Ed), Education in the Muslim world. Oxford: Symposium Books. pp. 41-54.

Slattery, P. (2006). Curriculum development in the postmodern era ( $2^{\text {nd }}$ edition). New York: Routledge.

White, R. (1988). The ELT curriculum: Design, innovation and management. Oxford: Basil Blackwell Ltd.

Young, M. F. D. (1998). The curriculum of the future: From the 'New sociology of education' to a critical theory of learning. Philadelphia, PA: Falmer press. 